Os professores do $2^{\circ}$ Grau trabalham com alunos com dificuldades escolares e psíquicas variadas (inibição, distúrbios da personalidade, carências educativas), em classes comuns ou instituições especializadas. Esta pesquisa descreve certas situações identitárias mobilizadas nos professores confrontados a essas novas situações, na relação com 0 saber, nas práticas e nas relações com os alunos. Professores; dificuldades escolares; conflitos identitários

TEACHERS OF THE SECONDARY AND PUPILS IN DIFFICULTY: PSYCHICAL DYNAMICS AND IDENDITY CONFLICTS The secondary schoolteachers work with pupils in school and psychic difficulty varied (inhibition, personality di sorder, educational deficiencies), in ordinary classes or specialized agenci es. This research describes certain identity stakes mobilized in thereport/ratio with the knowledge, the practicesand the relations with the pupils, in the teachers confronted with these new situations. Teachers, educational deficiencies; identity conflicts

\section{PROFESSORES E ALUNOS COM DIFICULDADES ESC O LARES: QUAIS SÃO AS DINÂMICAS PSÍQUICAS?}

\author{
Bernard Pechberty \\ Tradução: Inesita M achado
}<smiles>C1=C2C=C1C2</smiles>

crescente diversidade dos alunos, seus sucessos ou fracassos, seus percursos sociais, culturais e psíquicos manifestam-se em classes comuns e nas estruturas especializadas que a Educação nacional estabeleceu para remediar dificuldades escolares. A exigência democrática de ensinar a todos negligencia a questão das dinâmicas psíquicas mobilizadas nos professores para esses novos tipos de laços educativos. As dificuldades dos alunos em sua grande diversidade (inibição, recusa em aprender, fobia escolar, problemas graves de identidade, heterogeneidade cultural e social) conduzem a uma grande adaptação e a uma profunda mudança da identidade profissional do professor, na maior parte do tempo, não elaboradas. A formulação profis-

Membro do Laboratório Educação \& Aprendizagem da Equipe Clínica Graphies da Universidade René Descartes (Paris V). 
sional, inicial e contínua, desconhece ainda de modo amplo essas questões. O s efeitos negativos resultantes são visíveis na prática: professores desorientados postos na incapacidade de ensinar. Assim, pesquisas clínicas e didáticas são fundamentais para avaliar e acompanhar esta "modificabilidade" da identidade "ensinante".

\section{UMA PESQUISA CLÍNICA COM ORIENTAÇÃO PSICANALÍTICA}

Essa pesquisa exploratória diz respeito à identidade pessoal e profissional dos professores do $2^{\circ} \mathrm{G}$ rau, trabalhando em classes comuns ou especiais. D oze entrevistas clínicas foram realizadas com professores, de idades e disciplinas variadas (letras clássicas, modernas, história e geografia, ciências, matemática, educação física e esportiva, tecnologia, artes plásticas). Eles trabalham em escolas comuns ou situadas em zonas de educação prioritária, nas Segpa ${ }^{1}$, em classes de recuperação, em estabelecimentos de tratamento (unidade médica e pedagógica, hospital-dia). Essas estruturas especial izadas recebem alunos com dificuldades variadas, de aprendizagem ou comportamental, com problemas de acesso ao saber simbólico e abstrato (Segpa), distúrbios psicóticos da personalidade (hospital-dia), deficiências físicas (unidade médica e pedagógica), comportamentos a-escolares (zonas de educação prioritárias), desinvestimento escolar, condutas psicopáticas (classes de recuperação).

0 objetivo era esclarecer os elementos estável e dinâmico da identidade do professor confrontada com essa diversidade de alunos; tratava-se também de identificar o conflito das representações, dos afetos, as mudanças físicas manifestas e latentes que possibilitam a cada sujeito manter uma posição de professor adaptada a esses novos públicos.

O s conflitos psíquicos são particularmente interessantes, pois exprimem dinâmicas numa personalidade; são motores ou inibidores. Solicitam vários níveis do Si e fazem laço entre a realidade externa - vivida pela pessoa - e a realidade interna. M obilizam também funcionamentos defensivos ou de desapego (Lagache, 1958) em relação a situações, afetos e representantes pulsionais internos muito violentos.

Cada entrevista clínica foi conduzida com as seguintes questões, "como você vê seus alunos?", "como você se representa o ensino de sua disciplina?", "o que os alunos esperam de você?", complementadas por um desenho livre. O s resultados apóiam-se 
sobre a análise das representações e dos afetos expressos, sobre o inventário dos temas e construção de um conteúdo latente relativo ao equilíbrio físico e profissional.

N ossas questões eram: quais são os remanejamentos da identidade do professor induzidos pela adaptação a públicos com identidades diversas? A adolescência, elemento comum entre os alunos, seria um fator atuante sobre a personalidade profissional do professor? Enfim, se cada entrevista descreve um certo sistema de equilíbrio próprio à pessoa, podemos também identificar tendências recorrentes que se encontram na série de entrevistas?

\section{TEMAS PEDAGÓGICOS DOMINANTES}

A dificuldade em dar sentido, em transmitir a disciplina - A maioria das entrevistas ressalta a dificuldade em transmitir, em ensinar a disciplina e dar-Ihe sentido. $\mathrm{N}$ as escolas comuns, 0 ensino é possível: $M$ argot trabalha sem problemas com suas "boas classes". Para os professores de escolas sensíveis, ZEPs2 ou hospital-dia, a transmissão da matéria, "passá-la ao outro", é problemática, para um aluno que de início não a quer necessariamente. $\mathrm{N}$ em a acolhida positiva da disciplina, nem o desejo de aprender vêm de imediato.

Atitudes relacionais dos professores e dos alunos: atitudes privilegiadas que se destacam, como desafiar, fazer face, são fre qüentes. $M$ argot, diante da não demanda de seus alunos em relação às letras clássicas, deve inventar para se comunicar com eles e conseguir ensinar. Ela aceita mudar, clivar-se (ver abaixo), para inventar pedagogicamente. N as ZEPs, o desafio é maior, trata-se de sustentar uma situação de ensino, mas também de fazer com que os alunos "aceitem a escola". Esta posição expressa-se de modo ideológico, afetivo ou em termos de ajuda estruturante. 0 desafio também tem ressonâncias íntimas: Julie ensina aos alunos deficientes e teve seu irmão na mesma situação, Paul ouve os ecos de sua adolescência militante para mudar os valores de seus alunos. O utras relações operam-se, como sucitar a palavra dos alunos, em resposta a sua própria, dominar a situação de ensino e instituir uma relação com o saber intangível.

U ma atitude particular dos alunos é descrita: eles pedem ao professor que se exponha enquanto sujeito. E Ihe perguntam: por que aprender isso? Por que a escola? (e isto evoca a demanda adolescente de "sentir-se real", posta por Winnicott). Diante deste questionamento que expressa desinteresse, recusa e ao mesmo 
tempo necessidade de reconhecimento, as respostas dos professores são diversas: ir buscar o aluno, criar um ambiente de segurança pessoal em que a disciplina pode ter sentido, dar vida ao grupo classe. I sto evoca a área transicional (W innicott), em que 0 aluno tem 0 sentimento, a impressão, de ter "encontrado/criado" os objetos de saber.

$\mathrm{N}$ ecessidade de encontrar a pes soa dos alunos (elementos pessoais, familiares, sociais) na administração da classe e da disciplina - A maior parte dos professores fala da necessidade de levar em conta a realidade pessoal de seus alunos, do ponto de vista adolescente, familiar ou social. 0 espaço psíquico do lado de fora do social ou dos próprios alunos ligase ao do professor - é preciso aceitar, trabalhar com, sem cair na confusão. Esta integração se faz na disciplina (evocação temática da adolescência, das situações familiares ou sociais em educação cívica). N as ZEPs, esse levar em conta é marcado pelos termos utilizados (relação à "rua que invade a escola", "crianças perdidas", para Sandra; "que mundo", para Paul). Sozinha nas Segpa, M arie mantém uma relação com sua classe fechada ao redor de si e de sua disciplina. N os locais de tratamento, os professores não podem negar as deficiências ou dificuldades psíquicas dos alunos, ainda que sejam tentados a isso.

O s métodos psi cológi cos: crítica ao curso magistral, aporte do trabal ho em grupo, da pedagogia diferenciada, importância das relações com os alunos - É preciso distinguir os lugares em que a estrutura classe é mantida 
(escola, Segpa, ZEP) e os lugares em que este quadro não existe mais (hospital-dia, classe de recuperação). As escolhas de métodos pedagógicos são abordadas quando a transmissão aluno-professor não se opera mais. A metade dos professores de colégio exprime uma forte crítica ao curso magistral como modo dominante de transmissão. Este é dito formal, ineficaz, e não favorece a atividade dos alunos. 0 silêncio no curso é associado à morte psíquica. Três professores relatam práticas generalizadas de trabalho de grupo, dois de entrevistas individualizadas (sobre a autoavaliação dos alunos na disciplina, e sobre seu lugar na escola). Essa prática converge para o reconhecimento da pessoa do aluno, na classe e na vida escolar. A formação de grupos é vivida segundo um modelo implícito de vida familiar, ou, ao contrário, como referência ao meio de trabalho adulto futuro, transposto para a classe. N ão são apenas técnicas pedagógicas, mas escolhas relacionais que marcam um estilo particular de ensino e de relação com os alunos. 0 interesse do grupo é também introduzir um terceiro elemento em que 0 ensino magistral tornou-se problemático para o professor. Corinne conta como se desinibiu ousando introduzir no início da relação magistral a palavra, o debate, afetos. Para M ichel, o interesse do trabaIho de grupo em tecnologia é ligar à sociabilidade "de rua" dos alunos o futuro trabalho social. Essa pedagogia de grupo corresponde a uma necessidade de romper a es- trutura de classe, julgada artificial, de personalizar a pedagogia, de dar ao professor um outro lugar. Esta exigência é confirmada nas unidades de tratamento: as relações aí são muito individualizadas, os pequenos grupos flutuam de acordo com a saúde dos alunos, as idades se misturam. N enhum dos três professores se queixa. Annie não quer voltar à escola, em que os ritmos comuns impedem a relação pessoal. Carole dedica-se a uma violenta crítica à escola em que trabalhou.

\section{ANÁLISE QUALITATIVA: EQUILÍBRIOS PSÍQUICOS E IDENTIDADE PROFISSIONAL}

Cada discurso de professor estabelece elementos de seu "Si profissional"; esta categoria designa as diferentes instâncias psíquicas conscientes e inconscientes mobilizadas no exercício da profissão. Ela reagrupa a representação do si, de organizar a relação com 0 saber, com a disciplina, com a pedagogia. As entrevistas descrevem vários modos de adaptação aos diversos alunos, desestabilizantes, que não entram na relação de formação familiar com o professor.

Dois níveis de análise foram mantidos: a) as relações com o saber e com os alunos, b) as dinâmicas e conflitos mobilizados (sofrimentos, angústias, prazer)- mecanismos de defesa e posturas psíquicas e profissionais de desapego. 


\section{AS RELAÇÕES COM O SABER E COM OS ALUNOS}

A relação com o saber é objeto de uma das três questões postas. U tilizamos esta noção na pespectiva dos trabalhos da equipe do Cref (Beillerot et al., 2000). H á uma dimensão didática, mas também social e subjetiva, em que afetivo, cognitivo, consciente e inconsciente estão ligados. 0 saber escolar diz respeito à identidade "ensinante" de várias maneiras: pode ser um lugar de pesquisa, de domínio, de renovação, de tédio, carregado de ambivalência, valorizado ou não.

D ois eixos se cruzam: 1) a relação íntima, atual e evolutiva do professor com seu saber, sua disciplina de referência; 2) as representações dos alunos, nas quais as entrevistas desenham tipos de alunos gratificantes, esperados, ou desestabilizantes e recusados. Os trabalhos clínicos mostraram de que modo essas representações correspondem a partes do "si aluno" do professor, não sabidas por ele e "postas projetivamente nos alunos" (Laville, 2000) na continuidade da imagem do aluno que ele foi, que ele idealiza, ou que ele tende a rejeitar (Filloux, 1996). Assim, concebemos a hipótese de que um certo tipo de aluno "contado" faz laço com o eixo da relação com o saber do professor. As representações de alunos "satisfatórios" ou "insatisfatórios" são o sinal de ordenamentos psíquicos em relação ao saber e ao contexto. Aquilo que é insuportável indicará por exemplo um limite do comprometimento psicoprofissional e didático próprio ao professor.

\section{RESULTADOS GERAIS}

As entrevistas mostram a grande variedade de respostas dos professores, e nenhuma é intei ramente comparável a outra. N um plano global, aparecem diferenças entre professores de escolas comuns, que trabalham também em Segpa e em classes tecnológicas, os de ZEP e aqueles que trabalham em estabelecimentos de tratamento. 0 s professores de escolas comuns posicionam claramente seus alunos ao lado da disciplina, como eles mesmos aí se formaram: a transmissão do saber é possível. O s três professores de ZEP descrevem de que modo a situação escolar não tem um sentido imediato para muitos alunos. 0 espaço psíquico do lado de fora invade a classe. Os alunos são qualificados como "crianças perdidas", "submetidas a enormes dificuldades sociais", 
"pobres crianças a que é preciso estender a mão". O s professores devem tornar visíveis aos alunos sua implicação pedagógica para que a relação exista. N uma estrutura de tratamento, a relação com a disciplina também é modificada.

Primeiro encontro com a disciplina - A metade dos professores fala espontaneamente da importância de uma experiência de "primeira vez" entre eles, os alunos e a disciplina. Este primeiro encontro tem vários sentidos: ele é o signo de uma experiência fundadora, traz um prazer específico, mas é também uma prova, pois representa a dificuldade em estabelecer o "triângulo pedagógico", isto é, uma comunidade identificatória em que alunos e professores reconheçam-se mutuamente em torno do saber escolar.

Idades reais e psíquicas: um adolescente pode aprender? - As entrevistas exprimem várias atitudes em relação à adolescência dos alunos. Esta é com freqüência evitada, negada, às vezes reconhecida e integrada nas representações do professor. 0 aluno é posto como criança ou como jovem adulto, o que indica uma dificuldade dos professores em se identificar com seus alunos. A tendência em situar uma experiência privilegiada na $5^{\text {a }}$ série, tempo institucional de um primeiro encontro com a disciplina, é também a de um aluno vivido como uma criança, o que possibilita ao adulto colocar-se numa relação imaginária de tipo parental ligada à infância, e não à adolescência, mais difícil de aceitar na classe. A idade não parece ser significativa nos locais de tratamento, em que os professores encontram alunos "adolescentes", de idades variadas, nas relações em pequenos grupos ou individualizadas.

\section{IDENTIDADE "ENSINANTE" E SABER: ELEMENTOS CLÍNICOS}

Vou resumir aqui algumas figuras da relação com o saber expressas nas entrevistas e referidas aos tipos de estabelecimento. Este se inscreve num equilíbrio encontrado - precário ou mais estável - entre a imagem de si profissional e as representações dos alunos. Evolutiva, esta relação inclui aspectos explícitos e inconscientes. Sua mobilidade depende do percurso pessoal do professor e do público de alunos encontrado. 


\section{Escolas comuns}

1) Entre distância e proximidade de alunos: invenção de outros model os de ensino

Christiane justapõe duas experiências em história e geografia: ela transmite saberes formais, distanciados, em que domina o escrito (história/geografia) e um ensinamento vivo, oral (educação cívica) em que organiza debates e se vê então em contato com os alunos e suas questões. Foi por meio dessa matéria que ela evoluiu e permitiuse ensinar de outra maneira. Ela se desinibiu em relação à formação recebida e investiu o saber de outro modo. Um intervalo em sua profissão, as dificuldades escolares de seu filho possibilitaram-Ihe considerar a palavra dos alunos e inventar. Psiquicamente, Christiane vive a transmissão clássica como uma perda de contato com os alunos. 0 debate Ihe possibilita ficar em posição parental em relação ao grupo-classe, mas ela sente-se ameaçada por uma proximidade muito sedutora com os alunos.

2) Clivagem na identidade profissional

Com dois públicos diferentes em idade e estatuto, $M$ argot não pode transmitir as letras clássicas ao idêntico. Com as classes gerais, ela reproduz a rel ação adquirida com sua disciplina, que deve ser modificada nas classes de tecnologia, que não têm uma demanda particular, e ali ela deixa a iniciativa pedagógica aos 
alunos (escolha dos textos), expõese relacionalmente e reajusta seus objetivos. Esta clivagem das duas experiências possibilita-Ihe não comparar os dois tipos de alunos e trabalhar de forma diferente.

\section{Segpa}

3) U m ensino imutável

0 ensino de ciências, transmitido por $M$ arie nas Segpa, é preciso, intangível. Esta imutabilidade está ligada a uma dimensão defensiva observável: $M$ arie teme 0 imprevisível da expressão "caracterial" de seus alunos e sua agressividade adolescente. Ela transforma então seu medo em desejo de controlar a situação pedagógica, pensamentos e atos de seus alunos. Ela transmite os conteúdos de ciências, numa relação dual que põe seus alunos adolescentes numa posição asseguradora, mas que corre o risco de ser infantilizante.

\section{Escolas ZEP}

Para o professor, trata-se aqui de fazer com que 0 aluno goste da escola, transmitir conteúdos e criar um laço de identificação entre ele e seus alunos.

4) Retorno a um saber e a questões da infância

Sandra, em ciências, reconhece um saber a seus alunos: uma ex- periência de existência, do corpo, da vida, das sensações que teriam deixado neles questões sem resposta, esquecidas porém ativas. Ela escuta, remobiliza essas vivências infantis em seus alunos e propõe os conhecimentos das ciências físicas como um esclarecimento dessas experiências ao mesmo tempo singulares e universais. A isso se acrescenta uma pedagogia individualizada e de proximidade. Sandra adota uma posição maternal, ou maternante, em sua transmissão do saber; em contrapartida, teme uma destrutividade mais adolescente em relação a esse tecido pedagógico e relacional. Isto provoca a situação descrita por W innicott na emergência da área de ilusão, em que a mãe traz uma segurança e em que o bebê constrói a ilusão de ter criado aquilo que ele recebe. 0 objeto psíquico "encontrado/criado" é o primeiro modelo das aquisições culturais.

5) U m saber social, de grupo

$M$ ichel, em tecnologia, transmite um saber instrumento, que suscita questões antes de chegar a um resultado ou a um produto. Ele generaliza em sua classe a iniciativa de projeto e o trabalho de grupo, vivo, explicitamente oposto a um ensino tradicional, vivido como silencioso, morto. Para Michel, a relação magistral é portadora de angústia depressiva: sua tomada de posição pedagógica inversa Ihe possibilita agir. 0 trabalho de grupo toma então um lugar central, serve de terceiro na relação de $M$ ichel com seus alunos e o situa de outro 
modo como professor. Os alunos podem então transferir sua sociabilidade de rua nesse quadro; eles se põem como adultos no mundo do trabalho ("Só os professores não sabem que trabalhamos em grupo").

6) Transmitir e modificar os valores dos alunos

Paul sustenta seu ensino por um saber militante: ele expressa sua felicidade em estar com essas "pobres crianças a quem se deve estender a mão". Ele fala do sentido da escola que é preciso fazer aceitar, e secundariamente de sua matéria. Ele ensina história e geografia " $30 \%$ do tempo - no resto, eu faço enquadramentos". Ele descreve sua posição de "instrutor", respondendo à necessidade de retomar elementos que deveriam ter sido adquiridos muito mais cedo. O s raros exemplos didáticos situam-se no cruzamento das noções e dos val ores (a casa Terra e a solidariedade). O s alunos não compreendem o porquê de aprender geografia ou educação cívica. Seus valores individualistas não são aqueles que Paul defendia em sua adolescência, e são esses que ele gostaria de "passar" para eles. Ele evoca o tempo em que despertava para o militantismo e queria trabalhar com 0 Q uarto M undo - "É onde eu estou hoje". Seu ensino é sustentado por um desejo de encontrar e de formar hoje seus alunos por meio das escoIhas que emergiram para ele nessa época. 0 saber refere-se aqui a uma posição identitária e ideológica. 


\section{Classe de recuperação}

7) 0 ensino como pesquisa, como um modelo escolar deformante

M ichèle trabalha com classes difíceis, por escolha. Ela evoca seu percurso - uma tese em H istória, transferida depois para as Ciências da Educação, e em seguida a agregação da história e do ensino. O bservando suas próprias anotações escolares para preparar suas aulas, ela compreendeu que seus alunos "não entendiam nada". Ela então realizou essa ruptura por meio da psicologia de Freinet, e trabal ha por projetos, em grupo. A classe de recuperação interessa-lhe porque essa iniciativa de ensino é possível aí. Assim, ela vai voluntariamente de encontro aos alunos que esperam o curso tradicional, empurra-os para que sejam autônomos e atores. Aqui o aluno deve ser um indivíduo pesquisador, como ela mesma se tornou. Ela quer quebrar os moldes, os condicionamentos e se dá conta das resistências encontradas, mas mantém essa perspectiva militante: "Eu me sinto tudo, primeiramente educadora, e, mais do que transmitir saber, na classe de recuperação eu faço francês, história, informática, e eu penso que para realmente aprender história não se deve fazer apenas história, é preciso compreender o mundo em sua complexidade, e a história e a geografia fazem parte disso". $M$ ichèle posiciona-se num saber de pesquisa. Sua prática atual baseia-se numa clivagem com sua antiga experiência, que lhe possibilita posicionar-se de outro modo.

\section{Locais de tratamento}

\section{8) U m saber reparador do handicap}

Após o violento choque de angústia com a visão dos corpos dos jovens deficientes, depois de vários dias, Julie aceita ensinar na unidade médica e pedagógica. A existência de uma equipe de ensino e o tempo de reflexão auxiliam-na. Sua escolha é sobredeterminada, ela teve um irmão deficiente, e é um desafio "poder positivar" esse passado doloroso. $\mathrm{N}$ esse local, ela diz não mais fazer o papel de policial. 0 pequeno número de alunos não 0 obriga a manter uma certa imagem, "eu posso ensinar, não estou sobre um estrado falando alto". A ajuda física aos alunos muda seu papel habitual de professora: ela tira seus casacos, abre suas 
pastas. C ria-se uma cumplicidade que a remete a imagens familiares. Transpondo a angústia inicial, ela faz novas experiências: estimular um aluno cujo corpo é totalmente rígido "possibilita-lhe ter acesso a uma criatividade que está além de sua deficiência", pintar com alunos portadores de deficiências motoras "foi um momento de felicidade fantástica, havia pessoas em cadeiras de rodas que se levantaram para fazer esse exercício, porque tinham 0 desejo de colocar as mãos nas cores". A relação individualizada possibilita essa sensação: "É maravilhoso vêlos... descobrir coisas, e vê-los ter prazer em fazer coisas".

Conduzindo-os ao prazer, a uma outra forma de expressão e de existência, Julie redescobre seu próprio ensino. Ela sente a proximidade de seu trabal ho como o de um terapeuta, sem precisar ser um - "Também é um objetivo para mim fazê-los desabrochar". 0 termo prazer aparece várias vezes. 0 hospital, lugar de angústia, opõe-se ao ensinamento portador de vida: "As raras vezes em que fui ao hospital entendi por que os alunos (...) quer dizer que eles realmente saem do mundo do hospital. Eles criam, manipulam, brincam com as cores, com as formas, expressam-se". E Julie redescobre a origem histórica de sua disciplina, nascida na época de M aio de 1968.

Pela mutação da angústia ressentida diante da destruição do corpo, as artes plásticas tomam um novo sentido reparador. No contato com seus adolescentes, Julie desinibiu-se, e descobriu o sentido singu- 
lar de sua disciplina e das criações de seus alunos.

\section{9) Do ensino à psicopedagogia}

Carole desembaraça-se das amarras escolares em que ela não se reconhece mais. Ela não quer mais ensinar em escolas, em que o grupo e os ritmos comuns falseiam a experiência. Ela formou-se em Psicologia; no hospital-dia, trabalha com os atendentes e quer inventar uma outra relação com sua disciplina e com os textos literários. Ela tem consciência do valor das referências literárias para os adolescentes psicóticos e procura uma outra via de ensino, do lado da psicopedagogia clínica.

\section{OS CONFLITOS:}

SOFRIMENTOS PSÍQUICOS, ANGÚSTIAS, PRAZER. MECANISMOS DE DEFESA E POSTURAS DE DESAPEGO

Os relatos dos professores mostram de que modo os afetos são mobilizados. As duas gamas privilegiadas são o sofrimento psíquico, sua ligação com a angústia, e o prazer que remete ao conflito interno e a sua gestão, ao desejo e a sua carga inconsciente. Os níveis de angústia expressos são um indicador do equilíbrio encontrado. A angústia é um afeto central, paralisante ou criador, que ameaça a unidade da representação de si, mas é também um sinal que indica uma dinâmica, um re-equilíbrio. São evocadas representações, situações anxiogênicas, e é a partir daí que se elaboram modos de defesa e de desapego que orientarão um ou outro estilo ou prática pedagógica.

Esta pesquisa me conduziu a reatualizar a distinção proposta por $D$. Lagache entre mecanismos de defesa e de desapego. A defesa está muito próxima da angústia que ela visa combater. 0 desapego é uma distância suplementar tomada em relação à defesa interna; este introduz um jogo possível entre o Eu e 0 inconsciente, a possibilidade de criar e de inventar. A defesa volta-se para a redução urgente de situações de tensão e de desprazer, e as operações de desapego tendem à realização das possibilidades, mesmo ao preço de um aumento de tensão. Lagache dá como exemplo "a passagem da dissociação à integração; o desapego do objeto imaginário completado pela mudança de objeto; a familiaridade com as situações fóbicas que substitui a espera ansiosa da situação traumática e fantasmática; a substituição do controle à inibição, à experiência e à obediência. Em todos esses exemplos, a operação defensiva só é neutralizada quando uma operação de desapego a substitui". Assim, encontramos elementos nas entrevistas, próximos da angústia que eles visam combater, e outros que possibilitam um distanciamento, uma simbolização do conflito. São posturas, cenários, que formalizam esses desapegos possíveis. 


\section{1) Angústias}

A angústia aparece freqüentemente nas entrevistas e diz respeito a vários pólos:

- uma situação pedagógica e de ensino caótica e confusa, em que os limites da classe tradicional são requestionados ou invadidos pelo de fora (espaço social da rua, na ZEP, condutas de al unos fora das normas).

- o "Si profissional" do professor: equilíbrio difícil entre proximidade ou grande distância relacional com os alunos, medo dos afetos no encontro com a deficiência, medo de suas próprias reações agressivas diante da classe, medo de perder o contato, vivência de colapso, de ter que sustentar na escola uma missão institucional muito pesada.

- os alunos: medo de seus comportamentos imprevisíveis, medo de uma destrutividade adolescente em relação a uma pedagogia "envolvente", do tipo materno.

- a equipe: angústia depressiva diante de uma equipe de pares, instável, descontínua, que se opõe à necessidade de suporte, de permanência na ZEP.

- o grupo classe: dificuldade em administrar o peso do grupo na escola.

\section{Angústia e modos de compromisso pedagógico: ilustrações}

Christiane considera sinceramente a pessoa dos alunos, mas está dividida entre uma posi ção parental e sedutora. Sua angústia diz respeito à dificuldade em encontrar a distância relacional correta de seus alunos: medo de perder o contato ou de uma proximidade muito grande.

$\mathrm{N}$ os professores de ZEP, ou na Segpa, encontramos o medo da expressão pulsional imprevisível, violenta ou agressiva vinda dos alunos, ou de si mesmo. N a Segpa, $M$ arie teme as condutas irruptíveis possíveis de seus alunos, que ela percebia como "caracteriais". Essa angústia a leva a endurecer seu ensinamento, num desejo de controlar totalmente os atos, os pensamentos dos alunos, bem como a situação de ensino.

$M$ argot confronta-se com uma classe difícil, e não pode mais ensinar de modo habitual. Ela tem medo de não controlar sua própria agressividade diante das condutas "não clássicas" dos alunos de 8a série tecnológica: expressando uma vivência de morte, é preciso que ela "sobreviva". Ela descobre a saída "aprendendo algo sobre ela mesma", no contato com os alunos dos quais ela reconhece a grande maturidade humana e social.

$\mathrm{Na}$ ZEP, a excitação dos alunos é habitual e cotidiana. A partir daí, diferentes respostas se organizam. Sandra teme as pulsões agressivas dos "alunos grandes" que poderiam destruir a situação pedagógica envolvente e estruturante, do tipo maternante, que ela estabeleceu.

A angústia depressiva, a solidão e 0 abandono são perceptíveis em Paul: a vivência depressiva em seu 
trabalho difícil com os alunos é negada e refletida na instabilidade da equipe, dos colegas, que mudam todos os anos. 0 temor do silêncio e da inércia "sábia" dos alunos evoca uma experiência de morte em M ichel, o que lhe possibilita estabelecer, ao contrário, um laço pedagógico "vivo", conflitual, mas criativo.

A angústia de solidão encontra-se nos locais de tratamento: Julie expressa a angústia de estar sozinha com adolescentes deficientes e encontra a saída apoiando-se numa equipe de professores, e modificando sua relação com o saber.

Três professores falam de sua angústia por ter que administrar um grupo classe na escola. M ichèle, em classe de recuperação não teme seus alunos difíceis e a-escolares, mas ficou paralisada nas classes comuns em que ensinava magistralmente para alunos que não compreendiam.

\section{2) Elementos defensivos e de desapego}

Clivagens: encontramos com freqüência o mecanismo de clivagem, que permite ao professor diminuir e fracionar a carga afetiva angustiante. Campos da experiência. A experiência se diferencia: os valores afetivos do bom e do mau se distribuem, possibilitando escolhas e engajamentos. A identidade do professor pode então afirma-se rejeitando o que é "mau" numa zona que não se comunica mais com a escolha valorizada. 0 risco de confusão, a angústia de trabalhar numa situação caótica são assim evitados. As entrevistas indicam várias situações:

- Clivagem do Si profissional: M argot na escola cliva-se em sua identidade profissional para trabalhar com seus dois públicos, as "boas classes" e as $8^{a s}$ tecnológicas que não têm interesse pelas letras clássicas. Ela também está com essas duas classes, 0 que Ihe possibilita ensinar de modo diferente, aprender sobre ela e suas reações. Assim, ela pode viver experiências pedagógicas separadas e inventar.

- Clivagem do tratamento e da pedagogia com alunos deficientes, possibilitando a restauração narcísica em situação de ensino: após o primeiro choque de angústia induzido pela visão e a relação com o corpo deficiente de seus alunos, Julie expulsa essa violência sentida e a projeta para o pólo cuidador da unidade médica e pedagógica. 0 tratamento é clivado da pedagogia, o mau do bom, a angústia de destruição da possibilidade reencontrada de ensinar. Elemento defensivo e de desapego vão lado a lado. Sua disciplina, artes plásticas, irá tomar valores salvadores de vida, de reparação do sofrimento. 
Ação, todo-poder: os elementos defensivos dominam em $\mathrm{M}$ arie, nas Segpa, ligados ao medo do comportamento imprevisível de seus alunos. Seu estatuto de professora de escola "normal" é gratificante: para os alunos, ela representa o saber do ensino ordinário do qual eles são excluídos. Esta aura a deixa em uma posição idealizada, e a conduz a um papel parental superprotetor.

Projeção negação: diante do medo de perder o contato com seus alunos, Christiane projeta sobre eles seu próprio desejo de fazer laço com a palavra. Seu prazer pela expressão oral instala laços, debates, numa sedução de convívio, mas também erotizada, que comporta o risco de uma proximidade muito grande com os alunos (Cifali, 1994). A negação da gravidade dos problemas de seus alunos em hospital-dia possibilita a Annie senti-los "adolescentes como os outros". A participação nas sínteses dos cuidadores permite-lhe, no entanto, pensar sobre suas personalidades.

3) Três posturas pśquicas e profissionais de desapego - pesquisador, militante e reparador

0 desapego, as possibilidades de sublimação tomam corpo em posturas psíquicas e profissionais que sustentam o Si do professor; são ao mesmo tempo íntimas e sociais; indicam um equilíbrio encontrado entre a experiência do sujeito, as cenas conscientes e os fantasmas inconscientes, não diretamente observáveis, estilos de práticas e escolhas de valores. Estas conciliam o conflito psíquico, possibilitam ao desejo inconsciente dizer-se, pelo prazer de emergir, no confronto com as realidades escolares, com os alunos esperados e reais. Fazem laço entre a personalidade do professor, as realidades institucionais em que ele se inscreve e os valores ideológicos e culturais (D esprairies, 2000). As entrevistas desenham três posturas maiores. Estas posturas são distintas, mas interpenetram-se: as posturas militantes e reparadoras, já descritas por E. Enriquez, são próximas, possibilitam aprender e pesquisar. Pus numa única postura a daquele que aprende e a daquele que pesquisa, que me parecem específicas do mundo dos professores, eles mesmos antigos alunos.

- Postura de aprendiz e de pesquisador: com esta dinâmica psíquica, o desejo renova-se e cria de dois modos. Tanto o professor aprende algo em sua prática, aceita ser ensinado numa situação desestabilizante com alunos inesperados, quanto pode também pesquisar agindo. $M$ argot ensina e tem prazer em aprender: ela é posta numa posição de pesquisa por seus "bons" alunos, que a fazem descobrir novos autores. Ela divide com eles uma cultura 
comum das letras clássicas, e eles estão no prolongamento de sua própria formação. $\mathrm{Na}$ classe da $8^{\mathrm{a}}$ tecnológica, que não tem a mesma convivência cultural, ela modifica sua pedagogia, tem 0 sentimento de aprender, mas por suas próprias reações, pela gestão de situações conflituais - esses alunos formam-na na profissão de professora, com eles. A distância da ansiedade é próxima, 0 desapego inscreve-se no próprio risco. M ichèle identifica seus alunos com grandes dificuldades (classes de recuperação) em relação a seu próprio desejo de pesquisa, por suas escolhas de militância pedagógica. Lutando contra um modelo escolar apassivante, ela quer desenvolver em cada um uma curiosidade, um desejo de construção do saber no sentido da pedagogia de Freinet. Annie também tem o prazer da pesquisa, que renova sua relação com a disciplina, a matemática, através dos obstáculos e distúrbios do pensamento de seus alunos.

- Postura reparadora: reparar, curar, apagar o sofrimento, a ferida social ou da deficiência.

Reparar a infelicidade social: esta postura é legível entre os professores de ZEP nos termos empregados para o contexto social, no vocabulário de ajuda aos alunos desfavorecidos ou com dificuldades. Reparar a ferida física ou psíquica entende-se também nas instituições de tratamento: isso foi visto com Julie, que se vê como reparadora ao lado de seus alunos deficientes, levando para eles algo do prazer da vida.

- U ma postura militante, pedagógica ou política: esta posição implica o prazer de se confrontar com a diferença do outro para modificá-la. Paul fala de seu desejo em continuar a ensinar na ZEP, por razões ideológicas, políticas, mas também fortemente afetivas: com seus alunos, ele retoma a continuidade de sua própria adolescência militante. Ele se diz feliz com eles, quer mudar seus valores para modelá-los à imagem dos seus próprios. M ichèle estabelece uma prática na classe, em grupo e em projeto, numa perspectiva militante, mas no nível de suas escolhas pedagógicas, como M ichèle na classe de recuperação.

\section{CONCLUSÃO}

Esta pesquisa confirma a originalidade de cada experiência do professor diante dos diversos públicos de alunos. 0 equilíbrio singular descrito diz respeito a vários parâmetros: a relação com 0 saber, o conflito psíquico e sua gestão, as angústias, os mecanismos de defesa e de desapego, as posturas pessoais e profissionais, subjetivas e sociais. 
Comunicar e trabalhar com alunos que têm dificuldades requer uma inventividade pedagógica e psíquica, o que é atestado pelas temáticas apresentadas no início do texto: a crítica ao curso magistral, a importância do grupo, as relações pedagógicas diferenciadas implicam relações mais próximas e pessoais com os alunos. 0 reconhecimento de suas pessoas, de suas experiências ligadas ao social, à deficiência --, demanda novas identificações ao professor. Assim, os espaços psíquicos dos alunos comunicam-se de modo imediato com a identidade do professor. Sua relação com o saber, sempre singular, inscreve-se nesses contextos e nessas dinâmicas em que a pessoa e a relação individual têm um valor central.

0 papel da instituição também é importante: é sobre ela que o professor se projeta, se apóia ou reivindica. A classe tradicional está adaptada aos estudantes comuns e muito menos na ZEP, em que se trata de trabalhar com o grupo e com as pessoas, e portanto de modificar a pedagogia e o laço social. $\mathrm{N}$ os locais de tratamento, nenhum professor se queixa do desaparecimento da estrutura classe. Ao contrário, o pequeno número de alunos possibilita uma nova criatividade. Essa personalização das trocas, que também pode ser uma solidão, conduz a uma necessidade de apoio dos professores sobre a instituição, como equipe ou pólo de ensino, proporcionando a eles um pertencer coletivo e segurança.

A idade dos alunos e sua adolescência encontrada no enquadramento escolar induzem a uma instabilidade da identidade reinante: as representações dos alunos são, com freqüência, de crianças ou de adultos, como que para acompanhar ou evitar esse tempo intermediário, símbolo de mudanças incontroláveis. 0 professor também oscila entre esses dois pólos em sua identidade: identificação com a criança no aluno, suporte de um ideal adulto afirmado, mas carregado de incerteza.

\section{INSTABILIDADE E RENOVAÇÃO DO SI PROFISSIONAL}

É portanto com a pessoa inteira e com as diferentes instâncias do Si profissional que o professor poderá e deverá inventar modalidades relacionais, nessas situações pedagógicas específicas.

Q uatro traços maiores aparecem nas entrevistas:

1) os níveis psíquicos solicitados ao professor são múltiplos. As representações do Si ensinante são acompanhadas por 
imagens familiares (mãe iniciadora, enquadramento paterno), por um ideal adulto complexo, incerto, que o professor deve sustentar diante dos alunos, por elementos narcísicos e arcaicos que são mobilizados.

2) É em torno desse novo narcisismo que se organizam as dinâmicas psíquicas centrais. 0 professor está de fato confrontado a conflitos identificatórios sobre sua imagem de si, corporal, social ou profissional. Trata-se de "reconhecer-se no outro", aluno, seja ele deficiente, psicótico ou socialmente desadaptado. As operações de desapego inscrevem-se nesse primeiro reconhecimento em espelho com alunos freqüentemente estranhos à imagem de si do professor, herdada de sua formação.

3) Essa renovação identitária exigida por esses contextos de ensino é acompanhada por uma forte emergência pulsional, em que os riscos de derrapagem numa relação sedutora ou agressiva estão presentes.

4) U ma experiência de solidão profissional viva, criadora ou depressiva, necessita um novo apoio além da classe - rede ou instituição.

É esse conflito interno assumido que possibilita ao Si profissional do professor fazer face, modificar-se e inventar.

\section{UMA FORMAÇÃO CLÍNICA}

Essa exigência de renovação mostra a complexidade e a riqueza do trabalho do professor. A multiplicidade das dinâmicas em jogo aumenta a necessidade de uma elaboração das práticas profissionais de ordem clínica. U ma formação apropriada deve acompanhar mudanças identitárias nessas situações pedagógicas inéditas: é nesse momento que a reflexão didática faz sentido. Q uando os conflitos psíquicos tornam-se desestabilizantes e as angústias muito destrutivas, não é mais possível ensinar ou pensar, simplesmente. São mecanismos de sobrevivência que se impõem no lugar de uma verdadeira retomada do desejo de ensinar. 


\section{REFERÊNCIAS BIBLIOGRÁFICAS}

Beillerot J., Laville C. B., M osconi N . et al. (2000). Formeset formationsdu rapport au savoir. Paris: L'H armattan.

Cifali, M . (1994). Lelien éducatif: Contrejour psychanalytique. Paris: PUF.

D esprairies, F. G. (2000). La figure de l'autre dans l'école républicaine. Revue Internationale dePsychologia, 12.

Enriquez E. (1981). Petite galerie de portraits de formateurs en mal de modèles, Connexionsn 33.

Filloux J. (1996). Le contrat pédagogique, Paris: L'H armattan.

Ionescu S., Jacquet, M. \& Lhote, C. (2001). Les mécanismes de défenses. Paris: $\mathrm{N}$ athan.

Lagache D. (1958). La psychanalyse et la structure dela personnalité, La Psychanalyse. Paris: PUF

Laville C. B. (2000). Les enseignants entre plaisir et souffrance, Paris: L'H armattan.

M orvan, J. S. (1995). Education, psychologie clinique et recherche: Q uelles questions pour quels objets? M onografia em educação, Paris V.

Pechberty, B. (1999). Entre le soin et la formation: C onflits identificatoires dans la relation pédagogique. Revue Française de Pédagogie, 127.

W innicott, D . (1971). Jeu et realité. Paris: G allimard.

NOTAS

${ }^{1}$ A sigla Segpa quer dizer Sessões de ensino geral e profissional adaptado - tratase de classes no ensino secundário francês que se ocupam do ensino adaptado a alunos com distúrbios escolares específicos (problemas de abstração, atraso na aprendizagem) e que apresentam quadros próximos à deficiência intelectual leve.

20 significado de ZEP é Zonas de Educação Prioritária.

Recebi do em julho/2002. Aceito em setembro/2002. 